\title{
Effects of disease severity and medication state on postural control asymmetry during challenging postural tasks in individuals with Parkinson's disease
}

\author{
Fabio A. Barbieri a,b,*, Paula F. Polastri ${ }^{b}$, André M. Baptista ${ }^{a, b}$, Ellen Lirani-Silva ${ }^{a}$, Lucas Simieli ${ }^{\text {, }}$, \\ Diego Orcioli-Silva ${ }^{a}$, Victor S. Beretta ${ }^{a}$, Lilian T.B. Gobbi ${ }^{a}$

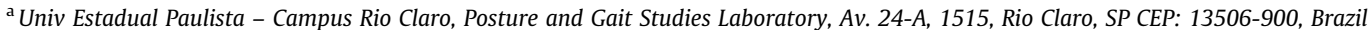 \\ ${ }^{\mathrm{b}}$ Univ Estadual Paulista - Campus Bauru, Laboratory of Human Movement Research, Laboratory of Information, Vision and Action, Av. Eng. Luiz Edmundo Carrijo \\ Coube, 14-01, Bauru, SP CEP: 17033-360, Brazil
}

\section{A R T I C L E I N F O}

\section{Article history:}

Received 31 May 2015

Revised 1 December 2015

Accepted 17 December 2015

Available online 29 December 2015

\section{Keywords:}

Parkinson's disease

Asymmetry

Medication

Postural control

\begin{abstract}
A B S T R A C T
The aim of this study was to investigate the effects of disease severity and medication state on postural control asymmetry during challenging tasks in individuals with Parkinson's disease (PD). Nineteen people with PD and 11 neurologically healthy individuals performed three standing task conditions: bipedal standing, tandem and unipedal adapted standing; the individuals with PD performed the tasks in ON and OFF medication state. The participants with PD were distributed into 2 groups according to disease severity: unilateral group $(n=8)$ and bilateral group $(n=11)$. The two PD groups performed the evaluations both under and without the medication. Two force plates were used to analyze the posture. The symmetric index was calculated for various of center of pressure. ANOVA one-way (groups) and two-way (PD groups $\times$ medication), with repeated measures for medication, were calculated. For main effects of group, the bilateral group was more asymmetric than CG. For main effects of medication, only unipedal adapted standing presented effects of PD medication. There was PD groups $\times$ medication interaction. Under the effects of medication, the unilateral group presented lower asymmetry of RMS in anterior-posterior direction and area than the bilateral group in unipedal adapted standing. In addition, the unilateral group presented lower asymmetry of mean velocity, RMS in anterior-posterior direction and area in unipedal standing and area in tandem adapted standing after a medication dose. Postural control asymmetry during challenging postural tasks was dependent on disease severity and medication state in people with PD. The bilateral group presented higher postural control asymmetry than the control and unilateral groups in challenging postural tasks. Finally, the medication dose was able to reduce postural control asymmetry in the unilateral group during challenging postural tasks.
\end{abstract} (c) 2015 Elsevier B.V. All rights reserved.

\footnotetext{
Abbreviations: PD, Parkinson's disease; H\&Y, Hoehn \& Yahr; MMSE, Mini Mental Status Examination; UPDRS, Unified Parkinson's Disease Rating Scale; $\mathrm{CoP}$, center of pressure; RMS, root mean square; AP, anterior-posterior; ML, medio-lateral; MA, most affected limb; D, dominant limb; LA, least affected limb; ND, non-dominant limb.

* Corresponding author at: Laboratory of Information, Vision and Action, Univ Estadual Paulista - UNESP, Av. Eng. Luiz Edmundo Carrijo Coube, 14-01, Bauru, São Paulo State CEP: 17033-360, Brazil.

E-mail address: barbieri@fc.unesp.br (F.A. Barbieri).
} 


\section{Introduction}

Previous studies have indicated that postural control during bipedal standing tasks is asymmetric in people with Parkinson's disease (PD) (Rocchi, Chiari, \& Horak, 2002; Carpenter, Allum, Honegger, Adkin, \& Bloem, 2004; Geurts et al., 2011). Asymmetric dopaminergic degeneration in the substantia nigra in regions of the cerebral hemisphere is one explanation for the motor and balance differences between the body sides (Kumar et al., 2003; Foster, Black, Antenor-Dorsey, Perlmutter, \& Hershey, 2008; Lewis et al., 2009). This pattern of asymmetry appears to remain unaltered during disease progression (Djaldetti, Ziv, \& Melamed, 2006), which seems to indicate no difference in the level of asymmetry between early unilateral - (Geurts et al., 2011) and moderated - bilateral - (Rocchi et al., 2002) stages of PD during bipedal standing tasks. Medication therapy, principally levodopa, is frequently taken to decrease the motor asymmetry caused by PD (Kumar et al., 2003). However, pharmacological treatment does not appear to improve postural control asymmetry in bipedal standing, which is probably explained by poor responses of body sway and muscular stiffness to dopaminergic medication (Bloem et al., 1996; Rocchi et al., 2002; Carpenter et al., 2004). On the other hand, Boonstra et al. (2014) and Boonstra, van Vugt, et al. (2014) indicated that people with PD in OFF medication state increased postural control asymmetry during postural tasks with perturbation in the sagittal plane (force plate movement), differently of patients in ON medication state (Geurts et al., 2011). Therefore, studies investigating balance asymmetries in ON and OFF medication state are needed in order to test the hypothesis that depletion of levodopa increase postural control asymmetry in PD. This is the first study to investigate the influence of disease severity on postural control asymmetry under (without) effects from medication during challenging postural tasks.

In a previous study, we found that postural control asymmetry is dependent on postural task challenge (Beretta et al., 2015). Individuals with PD presented higher postural control asymmetry in challenging postural tasks, such as tandem adapted standing and unipedal standing, compared to neurologically healthy individuals (Beretta et al., 2015). In addition, challenging postural tasks presented higher postural control asymmetry than bipedal standing in people with PD (Beretta et al., 2015). Previous studies have suggested that difficulty in adapting the magnitude and patterns of postural responses according to changes in postural demand (Horak, Dimitrova, \& Nutt, 2005) may explain the increase in postural asymmetry during challenging postural tasks. The combination of our findings, those of Boonstra and collaborators and the scarce knowledge related to asymmetries in balance, especially in a challenging posture (Mitchell, Collins, De Luca, Burrows, \& Lipsitz, 1995; Rocchi et al., 2002), raise the question of effects of disease severity and PD medication on postural control asymmetry during challenging tasks.

Therefore, the aim of this study was to investigate the effects of disease severity (unilateral and bilateral disease) and medication state (OFF and ON medication state) on postural control asymmetry during challenging tasks (tandem adapted standing and unipedal adapted standing) in people with PD. We hypothesized that disease severity and PD medication would not influence postural control asymmetry in the bipedal standing condition. However, for challenging postural tasks, we hypothesized that unilateral and bilateral individuals with PD would present similar asymmetry in postural control parameters since asymmetry remains unaltered during disease progression (Djaldetti et al., 2006), but higher asymmetry than neurologically healthy individuals. Regarding the effects of PD medication on postural control asymmetry, we expected that people with PD would display benefits of PD medication in reducing postural control asymmetry during challenging postural tasks, which would create more difficulty.

\section{Experimental procedures}

\subsection{Participants}

Nineteen people with PD and 11 neurologically healthy individuals (control group - 6 men) participated in this study. The participants with PD were referred to the current study by local neurologists. Diagnoses were confirmed by an expert neurologist according to the UK Brain Bank Criteria (Hughes, Daniel, Kilford, \& Lees, 1992). The individuals with PD were distributed into two groups according to disease severity (Hoehn \& Yahr - H\&Y -Hoehn \& Yahr, 1967; Schenkman, Wei Zhu, Cutson, \& Whetten-Goldstein, 2001): unilateral group ( $n=8-4$ men; H\&Y from 1 to 1.5$)$ and bilateral group $(n=11-6$ men; H\&Y from 2 to 3). The inclusion criteria of this study were: (i) aged equal to or over 60 years; (ii) have a current clinical diagnosis for idiopathic PD; (iii) score between stages 1 and 3 on the H\&Y scale (scores above PD stage 3 indicate disabling motor deficiencies and very different motor patterns to the previous stages, with, sometimes, loss of balance and independence); (iv) no signs of dementia based on results of the Mini Mental Status Examination (MMSE) (Folstein, Folstein, \& McHugh, 1975), adjusted according to patients' education level for the Brazilian population (Brucki, Nitrini, Caramelli, Bertolucci, \& Okamoto, 2003); (v) demonstrate no signs of other neurological diseases associated with PD; (vi) patients with PD had to be taking PD medication. Due to the inclusion criteria, ten people with PD were excluded from the study.

\subsection{Experimental design}

The study was approved by the research ethics committee of the São Paulo State University at Rio Claro - Brazil (\#0227/2012). The participants provided written informed consent to participate in the clinical and postural evaluation. 
The individuals with PD performed the tasks in the OFF medication state (after a minimum of $12 \mathrm{~h}$ withdrawal from PD medication), and then again $1 \mathrm{~h}$ after the participants had taken their dopaminergic medication; if the individuals were taking dopaminergic agonist medication, they were evaluated after a minimum of $24 \mathrm{~h}$ withdrawal from medication. We calculated the Levodopa Equivalent Dosage (LED) based on the medications that participants were taking (Tomlinson et al., 2010). The control group performed the evaluation once.

\subsection{Clinical evaluation}

First, an expert neuropsychiatrist performed an anamneses to characterize the PD and control group (CG), in particular the side on which the symptoms were occurring, complemented by the Unified Parkinson's Disease Rating Scale - UPDRS (Fahn, Elton, \& Committee MotUD, 1987) evaluation. Next, the patients were evaluated clinically to determine the stage of PD using the H\&Y scale and the motor portion (part III) of the UPDRS. In addition, cognitive aspects were analyzed using the MMSE (Almeida, 1998; Brucki et al., 2003) in all three groups.

\subsection{Determination of the most severely affected leg of people with PD and leg preference of the control group}

Footedness was assessed in the control group by asking all participants to stand on one leg (Sadeghi, Allard, Prince, \& Labelle, 2000). The limb that each individual initially chose to stand on was considered to be the preferred limb. For patients with PD, motor UPDRS items 20-23 and 25-26 were used to assess appendicular asymmetry (Uitti, Baba, Whaley, Wszolek, \& Putzke, 2005). The most severely affected limb was determined by finding the difference between the scores for the right and left limbs in the aforementioned UPDRS items. When this calculation resulted in a positive value, the right limb was considered to be the more severely affected limb, but when negative values were obtained, this indicated that the left limb was more severely affected.

\subsection{Postural evaluation}

Participants performed $30 \mathrm{~s}$ trials of standing tasks: bipedal standing, tandem adapted standing and unipedal adapted standing. Two force plates (AccuGait, Advanced Mechanical Technologies, Boston, MA), with a sample rate of $200 \mathrm{~Hz}$, were used to analyze postural control. For each of the three conditions, participants were instructed to stand quietly with their gaze directed at a target that was positioned at eye level $1 \mathrm{~m}$ in front of the participant.

For bipedal standing, participants positioned one foot on each force plate and were required to stand quietly in an upright position. Their feet were positioned in parallel to each other, at a similar distance from the pelvis. Participants performed three trials for this condition. For tandem adapted standing, participants positioned one foot on each force plate, but one foot was placed in front of the other. Participants performed three trials with each lower limb positioned in front. For unipedal adapted standing, participants used only one leg to stand on the force plate. They performed three trials with each limb. Due to the difficulties that many of the participants experienced when trying to stand on one foot, especially patients with PD, all participants were allowed to touch a wooden support as lightly as possible. All participants used this support during the unipedal standing trials. The order of each block of trials was bipedal standing first (condition a), tandem adapted standing second (condition b) and unipedal adapted standing last (condition $c$ ). In conditions b and c, whether the right or left foot was placed in front or used for unipedal adapted standing was randomized for each participant. Trials in which the participant lost their balance and a corrective step was performed were not analyzed; these trials were later repeated.

\subsection{Data analysis}

The mean center of pressure (CoP) signal was also calculated for each analysis. For bipedal and tandem standing, the resultant $\mathrm{CoP}$ signal of the ground reaction forces was determined in a 2-dimensional transverse plane by means of digital moment-of-force calculations for each force plate (Rocchi et al., 2002; Geurts et al., 2011). For unipedal adapted standing, the $\mathrm{CoP}$ was calculated in a similar manner as for the other conditions, but only for one force plate. In the tandem standing condition, the CoP of the limb positioned behind was used for the analysis.

The first $10 \mathrm{~s}$ of each recording were ignored to avoid potential disturbances resulting from delayed stabilization after the participant stepped onto the force plates. The data were then filtered with a fourth order low-pass Butterworth filter with a cut-off frequency determined by residual analysis $(10 \mathrm{~Hz})$. The following parameters were analyzed for each force plate: the total displacement of sway; the mean velocity of sway; the area of sway; and the root mean square (RMS) of sway displacement in anterior-posterior (AP) and medio-lateral (ML) directions. The asymmetry between the most affected and least affected limbs for patients with PD and the preferred and non-preferred limbs for the control group was analyzed using a symmetric index - SI (Robinson, Herzog, \& Nigg, 1987; Herzog, Nigg, Read, \& Olsson, 1989). For each trial, the symmetric index was determined. Next, the average for each participant in each condition was calculated.

$$
S I=\left[\frac{\text { value of } M A \text { or D limb }- \text { value of } L A \text { or ND limb }}{(\text { value of MA or D limb }+ \text { value of } L A \text { or } N D \lim b) / 2}\right] \times 100 \%
$$


where MA is the most affected limb, D is the dominant limb, LA is the least affected limb and ND is the non-dominant limb. A value of zero for index indicates that there is no difference between sides. Higher values indicated higher asymmetry of the individuals.

Statistical analyses were performed using SPSS software (version 18.0) for Windows $(\alpha<0.05)$. The data were normally distributed, and the assumption of sphericity was not violated, as verified by the Shapiro-Wilk and Mauchly tests, respectively. The symmetric index (absolute values) of the CoP parameters were analyzed using one-way (groups: unilateral group $\times$ bilateral group $\times$ control group) and two-way ANOVA (disease severity: unilateral and bilateral group $\times$ medication: OFF and ON medication state), with repeated measure for medication. The ANOVAs were performed separately for the three postural conditions. Both unilateral and bilateral people with PD were under the effects of PD medication in the data used to calculate the one-way ANOVA. When the ANOVA demonstrated significant differences; Tukey's post hoc tests were performed. In addition, the effect size (partial eta-squared) was measured for each statistical analysis.

\section{Results}

The characteristics and clinical variables are presented in Table 1 . There were no differences between the unilateral group, bilateral group and control group for anthropometric characteristics, age or cognitive aspect $(p>0.05)$. As expected, statistical analysis indicated effects of disease severity for H\&Y and motor UPDRS $\left(F_{1,17}=70.51 ; p<0.001 ; F_{1,17}=25.51 ; p<0.001\right.$, respectively), which presented higher values for the bilateral group. In addition, there was a main effect for medication, which demonstrated lower motor UPDRS $\left(F_{1,17}=2.73 ; p<0.001\right)$ under the effects of PD medication. Finally, there was no disease severity $\times$ medication interaction.

Regarding postural control asymmetry, for the main effects of group (Table 2), there were differences between the groups for the tandem adapted standing and unipedal adapted standing challenging postural tasks. Tukey post hoc tests indicated that the bilateral group presented higher asymmetry of area of sway in tandem adapted standing $\left(F_{2,27}=3.93\right)$ and unipedal adapted standing $\left(F_{2,27}=11.35\right)$ and RMS in both directions anterior-posterior $\left(F_{2,27}=4.69\right)$ and medio-lateral $\left(F_{2,27}=3.79\right)$ in unipedal adapted standing than the control group. For main effects of medication (Table 2), only unipedal adapted standing demonstrated effects of PD medication. People with PD in the ON medication state presented lower asymmetry of mean velocity $\left(F_{2,27}=8.37\right)$ compared to the OFF medication state.

There was disease severity $\times$ medication interaction for tandem adapted standing and unipedal adapted standing (Table 3). Under the effects of medication, the unilateral group presented lower asymmetry of RMS in the anterior-posterior direction $\left(F_{1,17}=7.72\right)$ and area $\left(F_{1,17}=9.03\right)$ of sway than the bilateral group in the unipedal adapted standing. In addition, the unilateral group presented lower asymmetry of mean velocity $\left(F_{1,17}=2.73\right)$, RMS in the anterior-posterior direction $\left(F_{1,17}=2.73\right)$ and area $\left(F_{1,17}=9.03\right)$ of sway in unipedal standing, and area of sway $\left(F_{1,17}=4.76\right)$ in tandem adapted standing after a medication dose.

\section{Discussion}

The aim of this study was to investigate the effects of disease severity and PD medication on postural control asymmetry during challenging tasks in individuals with PD. Table 3 presents a summary of the effects of group, medication and disease severity $\times$ medication interaction for each postural task. As we expected, there were no effects of disease severity and medication for the bipedal standing condition, which corroborated previous studies (Rocchi et al., 2002; Carpenter et al., 2004; Geurts et al., 2011). The main finding of this study was that the PD medication aided efficiency in challenging postural tasks, mainly for individuals with unilateral symptoms of PD. The individuals with PD in the bilateral stage presented higher postural control asymmetry than those with PD in the unilateral stage, under the effects of medication, and neurologically healthy individuals for tandem adapted standing and unipedal adapted standing, which is in contrast with our hypothesis. Therefore, asymmetry in postural control during challenging postural tasks seems to be influenced by both the effects of DP medication and disease severity.

The unilateral disease group demonstrated better motor function and balance, which were not as severe as the bilateral group (Hoehn \& Yahr, 1967). Humans use both legs to maintain their balance, and postural instability can result from impair-

Table 1

Means and standard deviations of the characteristics and clinical variables for each group. * - difference between ON and OFF medication state; \# - difference between unilateral and bilateral group.

\begin{tabular}{lllllrrll}
\hline Groups & $\begin{array}{l}\text { Medication } \\
\text { state }\end{array}$ & Age (years) & $\begin{array}{l}\text { Body weight } \\
(\mathrm{kg})\end{array}$ & $\begin{array}{l}\text { Body height } \\
(\mathrm{m})\end{array}$ & H\&Y (pts) & $\begin{array}{l}\text { Motor UPDRS } \\
(\mathrm{pts})\end{array}$ & $\begin{array}{l}\text { Cognitive } \\
\text { aspect }(\mathrm{pts})\end{array}$ & \multicolumn{1}{l}{$\begin{array}{l}\text { Levodopa equivalent dose } \\
(\mathrm{mg} / \mathrm{day})\end{array}$} \\
\hline Control & - & $69.18 \pm 7.37$ & $70.74 \pm 11.88$ & $1.65 \pm 0.05$ & - & & - & $29.00 \pm 1.61$ \\
Unilateral & OFF & $72.75 \pm 5.87$ & $75.67 \pm 7.46$ & $1.66 \pm 0.05$ & $1.5 \pm 0.10^{\#}$ & $15.87 \pm 2.90^{* \#}$ & $28.12 \pm 1.64$ & $175.79 \pm 222.05$ \\
& ON & & & & $1.5 \pm 0.10$ & $13.62 \pm 2.82$ & $28.62 \pm 1.84$ & \\
Bilateral & OFF & $73.90 \pm 6.37$ & $72.22 \pm 9.07$ & $1.60 \pm 0.07$ & $2.13 \pm 0.23$ & $31.90 \pm 8.36$ & $27.45 \pm 2.25$ & $599.60 \pm 296.50$ \\
& ON & & & & $2.09 \pm 0.20$ & $27.54 \pm 7.73$ & $28.09 \pm 1.92$ & \\
\hline
\end{tabular}


Table 2

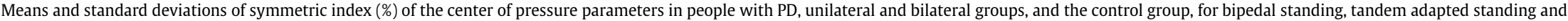

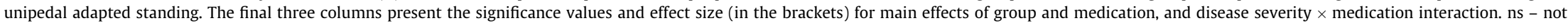
significant. $\mathrm{AP}=$ anterior-posterior; $\mathrm{ML}=$ medio-lateral.

\begin{tabular}{|c|c|c|c|c|c|c|c|c|c|}
\hline \multirow[t]{2}{*}{ Task } & \multirow{2}{*}{$\begin{array}{l}\text { Symmetric index } \\
(\%)\end{array}$} & \multirow{2}{*}{$\begin{array}{l}\text { Control } \\
\text { group }\end{array}$} & \multicolumn{2}{|l|}{ Unilateral group } & \multicolumn{2}{|l|}{ Bilateral group } & \multirow{2}{*}{$\begin{array}{l}\text { Effects of } \\
\text { group }\end{array}$} & \multirow{2}{*}{$\begin{array}{l}\text { Effects of } \\
\text { medication }\end{array}$} & \multirow{2}{*}{$\begin{array}{l}\text { Disease severity } \times \\
\text { medication interaction }\end{array}$} \\
\hline & & & $\begin{array}{l}\text { OFF medication } \\
\text { state }\end{array}$ & $\begin{array}{l}\text { ON medication } \\
\text { state }\end{array}$ & $\begin{array}{l}\text { OFF medication } \\
\text { state }\end{array}$ & $\begin{array}{l}\text { ON medication } \\
\text { state }\end{array}$ & & & \\
\hline & Total displacement & $27.61 \pm 16.61$ & $32.42 \pm 19.31$ & $33.88 \pm 24.19$ & $37.44 \pm 21.33$ & $39.93 \pm 23.20$ & ns & ns & ns \\
\hline & Mean velocity & $26.05 \pm 22.42$ & $35.63 \pm 21.54$ & $31.75 \pm 23.67$ & $34.70 \pm 20.67$ & $36.51 \pm 22.93$ & ns & ns & ns \\
\hline & RMS AP & $41.39 \pm 19.25$ & $34.97 \pm 16.31$ & $37.46 \pm 21.17$ & $41.94 \pm 22.33$ & $35.62 \pm 19.19$ & ns & ns & ns \\
\hline & RMS ML & $27.67 \pm 16.84$ & $32.78 \pm 19.28$ & $33.61 \pm 23.49$ & $38.66 \pm 21.68$ & $41.63 \pm 23.96$ & ns & ns & ns \\
\hline & Area & $36.95 \pm 22.26$ & $52.10 \pm 21.22$ & $55.57 \pm 27.56$ & $54.07 \pm 20.46$ & $47.61 \pm 19.00$ & ns & ns & ns \\
\hline & Total displacement & $26.28 \pm 15.94$ & $27.92 \pm 12.95$ & $29.35 \pm 11.90$ & $27.37 \pm 18.54$ & $29.68 \pm 11.27$ & ns & ns & ns \\
\hline & Mean velocity & $25.19 \pm 17.82$ & $25.31 \pm 10.81$ & $28.04 \pm 16.19$ & $26.07 \pm 12.76$ & $30.70 \pm 16.65$ & ns & ns & ns \\
\hline & RMS AP & $29.72 \pm 10.91$ & $23.68 \pm 13.26$ & $34.03 \pm 17.07$ & $30.47 \pm 16.68$ & $36.97 \pm 17.71$ & ns & ns & ns \\
\hline & RMS ML & $26.82 \pm 9.43$ & $26.59 \pm 11.30$ & $29.94 \pm 9.47$ & $33.16 \pm 19.52$ & $32.35 \pm 8.57$ & ns & ns & ns \\
\hline & Area & $47.89 \pm 19.74$ & $68.17 \pm 24.13$ & $52.07 \pm 15.16$ & $60.24 \pm 12.07$ & $66.14 \pm 17.20$ & $\mathbf{0 . 0 3}(0.43)$ & ns & $\mathbf{0 . 0 4}(0.47)$ \\
\hline & Total displacement & $21.15 \pm 16.27$ & $35.42 \pm 17.82$ & $28.56 \pm 16.98$ & $37.68 \pm 16.96$ & $32.28 \pm 19.08$ & ns & ns & ns \\
\hline & Mean velocity & $24.34 \pm 13.84$ & $44.12 \pm 19.75$ & $20.50 \pm 8.95$ & $40.51 \pm 19.20$ & $34.07 \pm 18.12$ & ns & $\mathbf{0 . 0 1}(0.57)$ & $\mathbf{0 . 0 2}(0.37)$ \\
\hline & RMS AP & $20.86 \pm 11.53$ & $49.78 \pm 20.48$ & $25.03 \pm 15.93$ & $34.69 \pm 21.05$ & $40.50 \pm 18.81$ & $\mathbf{0 . 0 1}(0.51)$ & ns & $\mathbf{0 . 0 1}(0.56)$ \\
\hline & RMS ML & $25.18 \pm 18.84$ & $34.13 \pm 19.27$ & $38.96 \pm 18.95$ & $54.99 \pm 21.43$ & $47.39 \pm 19.34$ & $\mathbf{0 . 0 3}(0.47)$ & ns & ns \\
\hline & Area & $28.66 \pm 16.80$ & $76.49 \pm 23.83$ & $50.29 \pm 29.32$ & $58.71 \pm 22.49$ & $70.50 \pm 16.12$ & $\mathbf{0 . 0 0 1}(0.68)$ & ns & $\mathbf{0 . 0 0 8}(0.59)$ \\
\hline
\end{tabular}


Table 3

Summary of the group, medication and disease severity $\times$ medication interaction for bipedal standing, tandem adapted standing and unipedal adapted standing. CG - control group.

\begin{tabular}{|c|c|c|c|c|}
\hline Effects & & Task & & \\
\hline Group & & NO & $\begin{array}{l}\text { YES: } \\
\text { Bilateral group > asymmetry to } \\
\text { CG }\end{array}$ & $\begin{array}{l}\text { YES } \\
\text { Bilateral group > asymmetry to CG }\end{array}$ \\
\hline Medication & & NO & NO & $\begin{array}{l}\text { YES: } \\
\text { OFF state > asymmetry to ON state }\end{array}$ \\
\hline \multirow[t]{2}{*}{$\begin{array}{l}\text { Disease } \\
\text { severity } \times \text { medication }\end{array}$} & $\begin{array}{l}\text { Unilateral } \\
\text { group }\end{array}$ & NO & $\begin{array}{l}\text { YES: } \\
\text { OFF state > asymmetry to ON } \\
\text { state }\end{array}$ & $\begin{array}{l}\text { YES: } \\
\text { OFF state > asymmetry to ON state }\end{array}$ \\
\hline & Bilateral group & NO & NO & $\begin{array}{l}\text { YES: } \\
\text { ON state: Bilateral group > asymmetry to unilateral } \\
\text { group }\end{array}$ \\
\hline
\end{tabular}

ment in even one leg. In the bipedal standing condition, it is theoretically possible for one leg to take over the function of the other leg (van der Kooij, van Asseldonk, Geelen, van Vugt, \& Bloem, 2007). This would be an effective compensation strategy if one of the legs was markedly affected (Geurts, Mulder, Nienhuis, \& Rijken, 1992). As the bipedal standing condition is a less challenging task, this compensatory strategy does not cause significant asymmetry in postural control. However, when the most affected limb is required for postural control, such as in the unipedal adapted standing condition, the asymmetry in postural control is evidenced in individuals with moderate (bilateral stage) PD. This type of postural task is more difficult and requires accurate functioning of the balance or postural control system (Frank, Horak, \& Nutt, 2000), which seems to exacerbate postural asymmetry. This finding may suggest that despite one leg being more affected than the other, the unilateral group was able to use the most affected leg when necessary, such as during the unipedal adapted standing condition, which did not happen for people with PD in the bilateral stage. Due to progressive impairment in dopamine striatal uptake in both cerebral hemispheres, which may be different between sides and the difference may increase over the years (JohnsonFrey, 2004; Binkofski, Buccino, Zilles, \& Fink, 2004; Potgieser \& de Jong, 2011), bilateral individuals present a severely affected limb that, when used for balance, impairs postural control and increases the chances of falling. In addition, effects of PD medication demonstrated a delayed onset, shorter duration and similar magnitude on the more affected side compared with the less affected side (Kumar et al., 2003). Due to the prolonged use of medication or increase in dopaminergic cells loss, the effects of medication become less efficient with disease progression (Baatile, Langbein, Weaver, Maloney, \& Jost, 2000; Katzenschlager \& Lees, 2002), which appears to increase the asymmetry. Therefore, these findings could indicate that postural control asymmetry increases proportionally with PD progression during challenging postural tasks, which impairs the use of the most affected limb and coincides with postural instability (Hsiao et al., 2014).

PD medication improved postural control asymmetry in people with PD in the unilateral stage during challenging postural tasks. The effects of medication on postural control in individuals with PD, mainly related to asymmetry, are still controversial. The effects of dopaminergic medication on postural control is difficult to predict, as some symptoms may improve, while others are resistant to medication or even worsen in the ON state (Beckley, Panzer, Remler, Ilog, \& Bloem, 1995; Visser et al., 2008; Mancini, Rocchi, Horak, \& Chiari, 2008). While previous studies indicated that PD medication does not seem to improve postural control asymmetry in bipedal standing (Bloem et al., 1996; Rocchi et al., 2002; Carpenter et al., 2004), Boonstra et al. (2014) and Boonstra, van Vugt, et al. (2014) indicated that without effects from dopaminergic medication, people with PD increase postural control asymmetry during postural tasks after postural perturbations in the sagittal plane. Our findings seem to advance this controversy, indicating that the benefits of PD medication on postural control asymmetry are dependent on disease severity (unilateral group) and postural task (unipedal adapted standing). One explanation for this dependency is that the PD medication response changes during the course of the pharmacological therapy, appearing to follow a consistent pattern: a mild and long-lasting response in the early stage, followed by a greater response with shorter duration resulting in waxing and waning between medication doses, and eventually, abrupt changes in response as if turned on and off by a switch (Duvoisin, 1989; Kumar et al., 2003). In addition, longitudinal studies have shown that longer duration of pharmacological treatment causes side effects, which may damage other aspects related to postural control asymmetry, such as proprioception, stiffness, and balance (Burleigh, Horak, Nutt, \& Frank, 1995; Jobst, Melnick, Byl, Dowling, \& Aminoff, 1997). Therefore, the medication is more effective by patients newly diagnosed with PD and those who have only suffered from the disease for a few years (Katzenschlager \& Lees, 2002). Regarding challenging postural tasks, the unipedal adapted standing condition seems to suppress the robust effects that PD medication presents on postural control asymmetry during the bipedal standing task. This type of task requires more mechanical body adjustments during the task, similar to tasks that 
require more balance, such as walking and running, which seems to indicate a control problem (Beretta et al., 2015). Thus, the combination of disease severity with the task challenge seems to indicate improvement in postural control asymmetry under PD medication.

Although the results of this study are consistent and relevant, this study has certain limitations. First, the number of participants was small, especially regarding individuals with PD in the unilateral stage. We suggest that a larger number of participants in this stage of PD should be analyzed to confirm our findings. However, the importance of our findings is not diminished since the selection of participants and clinical and postural evaluations were performed according to gold standard scientific procedures. Second, due to the difficulties that many participants experienced when trying to stand on one foot, especially patients with PD, all participants were allowed to touch a wooden support as lightly as possible. All participants used this support during the unipedal adapted standing trials. We know that this strategy, which could provide mechanical contact, could prejudice the findings of this study, as unipedal adapted standing should be the most difficult condition. However, the wooden support did not seem to provide substantial mechanical support for the participants. The support was a wooden bar secured in a pedestal with an unstable base, on which the participants could not support themselves since the pedestal would drop. Thus, the participants could only lightly touch the bar, although we did not measure the force applied to the wooden bar, which is important information. However, previous studies have indicated that attenuation of body sway (nearly 50\%) is independent of force applied (light touch or finger contact) (Jeka \& Lackner, 1994; Jeka \& Lackner, 1995). Therefore, these aspects and the higher postural control asymmetry for the unipedal standing condition seem to exclude the possibility of interference in our data. Third, we did not randomize the blocks of experimental conditions. This could bias the data and should be considered in our findings. Finally, $20 \mathrm{~s}$ of the postural task could be considered a short time to analyze postural control (Carpenter, Frank, Winter, \& Peysar, 2001). However, due to the difficulty of the unipedal condition, the individuals with PD were not able to perform more a longer period in this condition. In addition, CoP records of short duration capture the high frequency components of the signal, which reflect CoP control over center of mass and may characterize control strategies, which could be recommended for people with neurodegenerative disease (Carpenter et al., 2001).

\section{Conclusions}

We concluded that postural control asymmetry during challenging postural tasks was dependent on disease severity and PD medication in people with PD. Individuals with PD in the bilateral stage presented higher postural control asymmetry than those in the unilateral stage, under the effects of medication. In addition, the bilateral group also presented higher postural control asymmetry than neurologically healthy individuals in the tandem adapted and unipedal adapted standing conditions. Finally, the PD medication dose was able to reduce postural control asymmetry in the unilateral group during challenging postural tasks (unipedal adapted standing).

\section{Financial disclosures}

This research was supported in part by the Sao Paulo Research Foundation with scholarship to Fabio Augusto Barbieri (FAPESP \#2012/24040-9) and Victor Spiandor Beretta (FAPESP \#2013/00925-4). All other authors have nothing to declare.

\section{Author contributions}

FAB: study concept and design, acquisition of data, statistical analysis, interpretation of data, drafting and critical revision of manuscript for important intellectual content. PFP: study design, drafting and critical revision of manuscript for important intellectual content. AMB: acquisition of data, statistical analysis, interpretation of data, drafting and critical revision of manuscript for important intellectual content. ELS: acquisition of data, statistical analysis, interpretation of data, drafting and critical revision of manuscript for important intellectual content. LS: acquisition of data, statistical analysis, interpretation of data, drafting and critical revision of manuscript for important intellectual content. DOS: acquisition of data, statistical analysis, interpretation of data, drafting and critical revision of manuscript for important intellectual content. VSB: acquisition of data, statistical analysis, interpretation of data, drafting and critical revision of manuscript for important intellectual content. LTBG: study design, drafting and critical revision of manuscript for important intellectual content.

\section{Acknowledgement}

The authors thank FAPESP (\# 2012-24040-9; \# 2013/00925-4) for financial support.

\section{References}

Almeida, O. P. (1998). Mini mental state examination and the diagnosis of dementia in Brazil. Arquivos de Neuro-Psiquiatria, 56(3B), 605-612.

Baatile, J., Langbein, W. E., Weaver, F., Maloney, C., \& Jost, M. B. (2000). Effect of exercise on perceived quality of life of individuals with Parkinson's disease. Journal of Rehabilitation Research and Development, 37(5), 529-534. 
Beckley, D. J., Panzer, V. P., Remler, M. P., Ilog, L. B., \& Bloem, B. R. (1995). Clinical correlates of motor performance during paced postural tasks in Parkinson's disease. Journal of the Neurological Sciences, 132(2), 133-138.

Beretta, V. S., Gobbi, L. T. B., Lirani-Silva, E., Simieli, L., Orcioli-Silva, D., \& Barbieri, F. A. (2015). Challenging postural tasks increase asymmetry in patients with Parkinson's disease. PLOS ONE, 10(9), e0137722.

Binkofski, F., Buccino, G., Zilles, K., \& Fink, G. R. (2004). Supramodal representation of objects and actions in the human inferior temporal and ventral premotor cortex. Cortex, 40(1), 159-161.

Bloem, B. R., Beckley, D. J., van Dijk, J. G., Zwinderman, A. H., Remler, M. P., \& Roos, R. A. (1996). Influence of dopaminergic medication on automatic postural responses and balance impairment in Parkinson's disease. Movement Disorders, 11(5), 509-521.

Boonstra, T. A., Schouten, A. C., van Vugt, J. P., Bloem, B. R., \& van der Kooij, H. (2014). Parkinson's disease patients compensate for balance control asymmetry. Journal of Neurophysiology, 112, 3227-3239.

Boonstra, T. A., van Vugt, J. P., van der Kooij, H., \& Bloem, B. R. (2014). Balance asymmetry in Parkinson's disease and its contribution to freezing of gait. PLoS ONE, 9(7), e102493.

Brucki, S. M., Nitrini, R., Caramelli, P., Bertolucci, P. H., \& Okamoto, I. H. (2003). Suggestions for utilization of the mini-mental state examination in Brazil. Arquivos de Neuro-Psiquiatria, 61(3B), 777-781.

Burleigh, A., Horak, F., Nutt, J., \& Frank, J. (1995). Levodopa reduces muscle tone and lower extremity tremor in Parkinson's disease. Canadian Journal of Neurological Sciences, 22(4), 280-285.

Carpenter, M. G., Allum, J. H., Honegger, F., Adkin, A. L., \& Bloem, B. R. (2004). Postural abnormalities to multidirectional stance perturbations in Parkinson's disease. Journal of Neurology, Neurosurgery and Psychiatry, 75(9), 1245-1254.

Carpenter, M. G., Frank, J. S., Winter, D. A., \& Peysar, G. W. (2001). Sampling duration effects on centre of pressure summary measures. Gait E Posture, 13(1), $35-40$.

Djaldetti, R., Ziv, I., \& Melamed, E. (2006). The mystery of motor asymmetry in Parkinson's disease. Lancet Neurology, 5(9), 796-802.

Duvoisin, R. C. (1989). New strategies in dopaminergic therapy of Parkinson's disease: The use of a controlled-release formulation. Neurology, 39(11), 4-6.

Fahn, S., \& Elton, R.Committee MotUD. (1987). The unified Parkinson's disease rating scale. In S. Fahn, C. D. Marsden, D. B. Calne, \& M. Goldstein (Eds.), Recent developments in Parkinsońs disease (2nd ed., pp. 153-163). Florham Park: Mcmellam Health Care Information.

Folstein, M. F., Folstein, S. E., \& McHugh, P. R. (1975). "Mini-mental state". A practical method for grading the cognitive state of patients for the clinician. Journal of Psychiatric Research, 12(3), 189-198.

Foster, E. R., Black, K. J., Antenor-Dorsey, J. A., Perlmutter, J. S., \& Hershey, T. (2008). Motor asymmetry and substantia nigra volume are related to spatial delayed response performance in Parkinson disease. Brain and Cognition, 67(1), 1-10.

Frank, J. S., Horak, F. B., \& Nutt, J. (2000). Centrally initiated postural adjustments in parkinsonian patients on and off levodopa. Journal of Neurophysiology, 84 (5), 2440-2448.

Geurts, A. C., Boonstra, T. A., Voermans, N. C., Diender, M. G., Weerdesteyn, V., \& Bloem, B. R. (2011). Assessment of postural asymmetry in mild to moderate Parkinson's disease. Gait \& Posture, 33(1), 143-145.

Geurts, A. C. H., Mulder, T. W., Nienhuis, B., \& Rijken, R. A. J. (1992). Postural reorganization following lower-limb amputation - Possible motor and sensory determinants of recovery. Scandinavian Journal of Rehabilitation Medicine, 24(2), 83-90.

Herzog, W., Nigg, B. M., Read, L. J., \& Olsson, E. (1989). Asymmetries in ground reaction force patterns in normal human gait. Medicine and Science in Sports and Exercise, 21(1), 110-114.

Hoehn, M. M., \& Yahr, M. D. (1967). Parkinsonism: Onset, progression and mortality. Neurology, 17(5), 427-442.

Horak, F. B., Dimitrova, D., \& Nutt, J. G. (2005). Direction-specific postural instability in subjects with Parkinson's disease. Experimental Neurology, 193(2), $504-521$.

Hsiao, I. T., Weng, Y. H., Hsieh, C. J., Lin, W. Y., Wey, S. P., Kung, M. P., ... Lin, K. J. (2014). Correlation of Parkinson disease severity and 18F-DTBZ positron emission tomography. JAMA Neurology, 71(6), 758-766.

Hughes, A. J., Daniel, S. E., Kilford, L., \& Lees, A. J. (1992). Accuracy of clinical diagnosis of idiopathic Parkinson's disease: A clinico-pathological study of 100 cases. Journal of Neurology, Neurosurgery and Psychiatry, 55(3), 181-184.

Jeka, J. J., \& Lackner, J. R. (1994). Fingertip contact influences human postural control. Experimental Brain Research, 100, $495-592$.

Jeka, J. J., \& Lackner, J. R. (1995). The role of haptic cues from rough and slippery surfaces on human postural control. Experimental Brain Research, 103, $267-276$

Jobst, E. E., Melnick, M. E., Byl, N. N., Dowling, G. A., \& Aminoff, M. J. (1997). Sensory perception in Parkinson disease. Archives of Neurology, 54(4), 450-454.

Johnson-Frey, S. H. (2004). The neural bases of complex tool use in humans. Trends in Cognitive Sciences, 8(2), 71-78.

Katzenschlager, R., \& Lees, A. J. (2002). Treatment of Parkinson's disease: Levodopa as the first choice. Journal of Neurology, 249(2), 19-24.

Kumar, A., Mann, S., Sossi, V., Ruth, T. J., Stoessl, A. J., Schulzer, M., et al (2003). [11c]DTBZ-PET correlates of levodopa responses in asymmetric Parkinson's disease. Brain, 126, 2648-2655.

Lewis, M. M., Smith, A. B., Styner, M., Gu, H., Poole, R., Zhu, H., et al (2009). Asymmetrical lateral ventricular enlargement in Parkinson's disease. European Journal of Neurology, 16(4), 475-481.

Mancini, M., Rocchi, L., Horak, F. B., \& Chiari, L. (2008). Effects of Parkinson's disease and levodopa on functional limits of stability. Clinical Biomechanics, 23 (4), 450-458.

Mitchell, S. L., Collins, J. J., De Luca, C. J., Burrows, A., \& Lipsitz, L. A. (1995). Open-loop and closed-loop postural control mechanisms in Parkinson's disease: Increased mediolateral activity during quiet standing. Neuroscience Letters, 197(2), 133-136.

Potgieser, A. R., \& de Jong, B. M. (2011). Different distal-proximal movement balances in right- and left-hand writing may hint at differential premotor cortex involvement. Human Movement Science, 30(6), 1072-1078.

Robinson, R. O., Herzog, W., \& Nigg, B. M. (1987). Use of force platform variables to quantify the effects of chiropractic manipulation on gait symmetry. Journal of Manipulative and Physiological Therapeutics, 10(4), 172-176.

Rocchi, L., Chiari, L., \& Horak, F. B. (2002). Effects of deep brain stimulation and levodopa on postural sway in Parkinson's disease. Journal of Neurology, Neurosurgery and Psychiatry, 73(3), 267-274.

Sadeghi, H., Allard, P., Prince, F., \& Labelle, H. (2000). Symmetry and limb dominance in able-bodied gait: A review. Gait E’ Posture, 12(1), 34-45.

Schenkman, M., Wei Zhu, C., Cutson, T. M., \& Whetten-Goldstein, K. (2001). Longitudinal evaluation of economic and physical impact of Parkinson's disease. Parkinsonism and Related Disorders, 8(1), 41-50.

Tomlinson, C. L., Stowe, R., Patel, S., Rick, C., Gray, R., \& Clarke, C. E. (2010). Systematic review of Levodopa doses equivalency reporting in Parkinson's disease. Movement Disorders, 25(15), 2649-2685.

Uitti, R. J., Baba, Y., Whaley, N. R., Wszolek, Z. K., \& Putzke, J. D. (2005). Parkinson disease: Handedness predicts asymmetry. Neurology, 64(11), 1925-1930.

van der Kooij, H., van Asseldonk, E. H., Geelen, J., van Vugt, J. P., \& Bloem, B. R. (2007). Detecting asymmetries in balance control with system identification: First experimental results from Parkinson patients. Journal of Neural Transmission, 114(10), 1333-1337.

Visser, J. E., Allum, J. H., Carpenter, M. G., Esselink, R. A., Speelman, J. D., Borm, G. F., et al (2008). Subthalamic nucleus stimulation and levodopa-resistant postural instability in Parkinson's disease. Journal of Neurology, 225(2), 205-210. 